\title{
Comparison of Model High-Latitude Electron Densities With Millstone Hill Observations
}

\author{
J. J. SOJKA AND R. W. SCHUNK \\ Center for Atmospheric and Space Sciences, Utah State University \\ J. V. Evans, J. M. HOLT, AND R. H. WAND \\ Haystack Observatory, Massachusetts Institute of Technology
}

\begin{abstract}
Model predictions of the diurnal variations of plasma convection velocities and electron densities in the high-latitude ionosphere were compared with Millstone Hill incoherent scatter radar observations for an equinox day on which there was moderate magnetic activity. On the observation day, three major morphological features were evident at $500 \mathrm{~km}$, including a dayside high density region, a nightside mid-latitude trough, and a region of slightly enhanced densities in the auroral zone. Although the dayside high density region was due to solar EUV radiation, it was not symmetrical about local noon (1000-1900 LT sector) owing to the effect of horizontal transport. The nightside mid-latitude trough was the deepest, the widest, and reached its most equatorward latitude in the morning sector. The model was able to reproduce these two features quite accurately. In the dusk sector, the trough was filled in, and its latitudinal extent was restricted by a discrete auroral arc, a feature not included in the ionospheric model. Except for this arc region, the enhanced electron densities in the auroral zone were adequately described by the average precipitation fluxes used in the model. The observed plasma drift velocities were consistent with a two-cell, asymmetric convection pattern with enhanced flow in the dusk sector. Outside the polar cap, the fall-off of the magnetospheric potential with latitude was proportional to the inverse of the sine of colatitude to the fourth power. The convection pattern employed in the model included these features and had a $60 \mathrm{kV}$ cross-polar-cap potential. Efforts to reproduce the observed behavior by using a larger cross-polar-cap potential $(90 \mathrm{kV})$ or a symmetric pattern are also presented. These were generally less successful and demonstrate the sensitivity of the morphology of the $F$ region at high latitudes to the convection process.
\end{abstract}

\section{INTRODUCTION}

During the past few years, we have developed a comprehensive model of the convecting high-latitude ionosphere in order to determine the extent to which various chemical and transport processes affect the ion composition and electron density at $F$ region altitudes [cf. Schunk and Raitt, 1980; Sojka et al., 1981a, b, c, 1982a, b; Schunk and Sojka, 1982a, b]. Our numerical model produces time dependent, three-dimensional ion density distributions for the ions $\mathrm{NO}^{+}, \mathrm{O}_{2}^{+}, \mathrm{N}_{2}^{+}, \mathrm{O}^{+}, \mathrm{N}^{+}$, and $\mathrm{He}^{+}$. The model takes account of diffusion, thermospheric winds, electrodynamic drifts, polar wind escape, energy dependent chemical reactions, magnetic storm induced neutral composition changes, and ion production due to solar EUV radiation and energetic particle precipitation. One of the important results that emerged from these studies was that high-latitude ionospheric features, such as the 'main trough', the 'ionization hole', the 'tongue of ionization', and the 'aurorally produced ionization peaks', are a natural consequence of the competition between the various chemical and transport processes known to be operating in the high-latitude ionosphere. We also found that these features display a marked variation with season, convection pattern, and universal time (UT)

In order to determine the validity of our model, we have

Copyright 1983 by the American Geophysical Union.

$\mathrm{Pa}$

aper number $3 \mathrm{~A} 0799$.

148-0227/83/003A-0799\$05.00 compared model predictions with observations whenever possible. We compared plasma convection patterns predicted by our model with those observed concurrently at Chatanika, Alaska, and Millstone Hill, Massachusetts [Sojka et al., 1980]. These two incoherent scatter facilities operated over the same period of four days in June 1978 and provided data sets that were averaged to 24 hours in order to minimize the effects of individual substorms. The two radar facilities observed different diurnal patterns of horizontal plasma convection velocities owing to the displacement between the geomagnetic and geographic poles. In general, there was good agreement between the convection model and the different diurnal patterns observed at Chatanika and Millstone Hill.

For solar minimum, winter, and low geomagnetic activity conditions, we have compared the electron density and ion compositional variations that we obtained from our model with the Atmosphere Explorer (AE-C) satellite data presented by Brinton et al. [1978], and generally good quantitative agreement was obtained between theory and measurement [Sojka et al., 1981a, b]. However, the AE data were not organized with respect to universal time, and therefore, the large UT variation of electron density that our model predicts, which results from the displacement between the geomagnetic and geographic poles, could not be tested. To remedy this situation, we used the sun synchronous (fixed LT) nature and high time resolution of the ion density measurements from the DMSP F2 and F4 satellites to study the UT dependence of the high latitude ion density at $800 \mathrm{~km}$ [Sojka et al., 1982b]. Both the long term variation of the 
ion density on a time scale of days, and the orbit by orbit variations at the same geomagnetic location in the northern (winter) hemisphere for the magnetically quiet time period chosen show good qualitative agreement with the UT dependence predicted by our theoretical model for similar geophysical conditions.

Although the comparisons described above were useful in verifying some of the predictions of our ionospheric model, they were limited in that either averaged data or data along individual satellite tracks were used. In this study, we attempted a more comprehensive comparison of model predictions and observations. Specifically, we compared the predicted diurnal variations of plasma convection velocities and electron densities with measurements made at Millstone Hill on a geomagnetically moderately active day near equinox.

\section{Convection and Global Conditions}

The $F$ region ion densities and associated plasma drift velocities presented in this paper were obtained by the Millstone Hill incoherent scatter radar facility over a 24hour period beginning at 1326 UT on October 13, 1979. Millstone Hill is located at $42.6^{\circ} \mathrm{N}$ and $71.5^{\circ} \mathrm{W}$ (geographic) at an invariant latitude $(\Lambda)$ of $56^{\circ}$. The data were acquired over a latitudinal interval $52^{\circ} \leqslant \Lambda \leqslant 72^{\circ}$ by scanning the antenna in azimuth from east to north while holding the beam at a fixed elevation of $4^{\circ}$. Each scan took approximately $30 \mathrm{~min}$ to complete. At low latitudes the resolution $\mathrm{N}-\mathrm{S}$ is set by the scan rate $(4 \% \mathrm{~min})$ and the integration length $(30 \mathrm{~s})$ to be $\sim 1^{\circ}$ at an altitude of 500 $\mathrm{km}$. At high latitudes the resolution in latitude is set by the $300-\mathrm{km}$ length $\left(2^{\circ}\right)$ of the exploring pulse. The time resolution is set by the scan rate $(30 \mathrm{~min})$, which means that a given location in the ionosphere is revisited twice per hour.

The azimuth scan data described above yield estimates of the line of sight drifts over a range of radial distances and azimuths with respect to the radar. Vector electric fields were derived from these estimates by assuming that the line of sight drift could be represented in terms of an electrostatic potential:

$$
v_{p}=\mathbf{p} \cdot(-\Delta \Phi \times \mathbf{B}) / B^{2}
$$

where $v_{p}$ is the observed drift, $\mathbf{p}$ is a unit vector in the radar look direction, $\Phi$ is the potential, and $\mathbf{B}$ is the geomagnetic field. The contribution of the parallel component of the ion velocity is assumed to be negligible, $\mathbf{p} \cdot \mathbf{v}_{\|}$ $=0$. The potential was represented as an analytic function of UT, azimuth, and range, subject to the boundary condition $\Phi=0$ at the latitude of Millstone. A least squared fit to the data was computed. The vector velocity was then calculated from (1). This technique is described in more detail in Holt et al. [1983].

Figure 1 shows the drift velocities observed on October 13-14, 1979, plotted as a function of apex (or invariant latitude) and local magnetic time for a local time corresponding to the universal time of the center of each scan (this accounts for the curved sets of vectors shown). Unfortunately, in order to accommodate the large drifts seen near $1700 \mathrm{LT}(>1500 \mathrm{~m} / \mathrm{s})$, the scale is such that it is

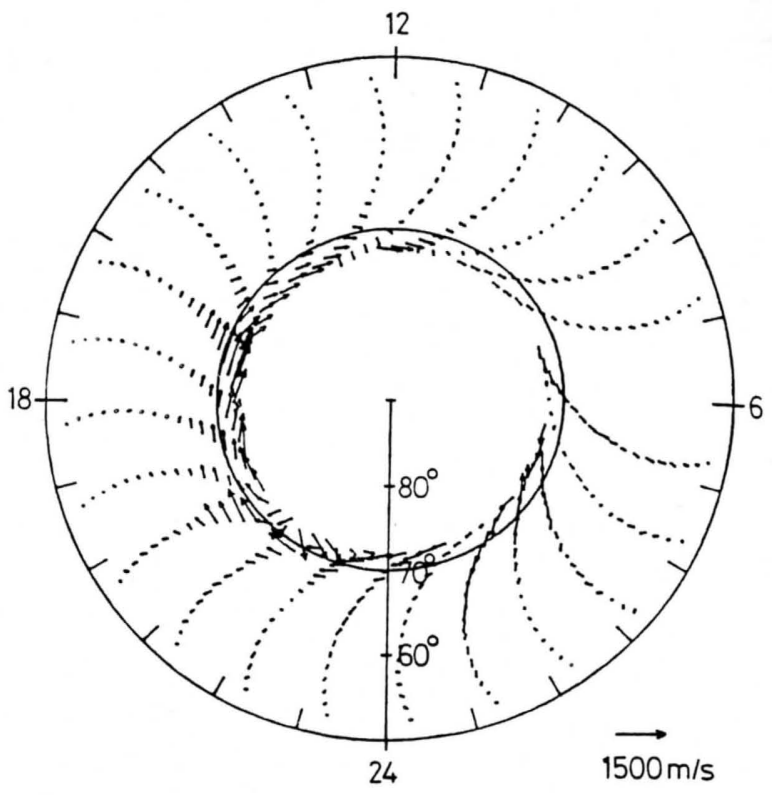

Fig. 1. Ion drift velocities measured by the Millstone Hill radar during the 24-hour period beginning at 1326 UT on October 13, 1979. The velocities are displayed in a local time-invariant latitude polar diagram.

difficult to show the speed and direction at other local times. In the afternoon sector, very marked westward flows are observed, the magnitude of which increases with latitude. At about $1800 \mathrm{LT}$ and $72^{\circ} \Lambda$, the maximum velocity for this 24-hour period is observed to be about $1500 \mathrm{~m} / \mathrm{s}$. There is no indication at the highest latitude of a flow reversal from the sunward to the anti-sunward direction, indicating that the polar cap boundary, which is identified by such a reversal, is somewhat poleward of $72^{\circ} \wedge$ in the afternoon sector. The flow velocities in the morning sector are particularly weak to the extent that this region is predominantly corotating with the earth. Indeed in this sector the vectors show a progressive rotation with latitudes and little change in length, suggesting that the solution for the fields becomes unreliable when they are weak and do not change with latitude. Over a sector from 1000 to $1300 \mathrm{LT}$ at $72^{\circ} \wedge$ there is a region where the plasma flows into the polar cap, while in the 2000 to $2300 \mathrm{LT}$ sector at $72^{\circ} \wedge$ there is strong outflow from the polar cap.

For the 24-hour period covered by the observation, the first 15 hours $(0700-2200 \mathrm{LT})$ were moderately active with an average 3 hourly $K p$ of $3^{-}$. The remaining nine hours were less active with an average $K p$ of 2 . Although the data shown in Figure 1 cover a 24-hour period, the time variation of the magnetospheric convection electric field cannot be readily inferred from a single corotating radar site. However, for a thorough comparison of model predictions and observations it is necessary to know both the local time and universal time (UT) variation of the magnetospheric electric field. Since the latter is unknown to a large extent, we selected three different model convection patterns, each of which was assumed to be UT independent for the 24 hour duration of the study. The three models were chosen to cover a range of magnetic activities somewhat greater than those described for the 
TABLE 1. Convection Model Parameters

\begin{tabular}{clrcccc}
\hline Model & $K p$ & $A p$ & $\phi_{c t}$ & Polar radius & Polar Offset & Polar $E$ Distribution \\
\hline A & 5 & 35 & $90 \mathrm{kV}$ & $18.5^{\circ}$ & $2.0^{\circ}$ & Dusk enhanced \\
B & 3 & 15 & $62 \mathrm{kV}$ & $17.9^{\circ}$ & $2.2^{\circ}$ & Dusk enhanced \\
C & 2.25 & 9 & $52 \mathrm{kV}$ & $15.0^{\circ}$ & $2.3^{\circ}$ & Symmetric \\
\hline
\end{tabular}

All 3 models use a fall-off coefficient of 4 .

observation day. Table 1 lists the parameters associated with the three convection models. Model A is appropriate for an average 3 hourly $K p$ of 5 and has a cross-tail magnetospheric potential $\left(\phi_{c t}\right)$ of $90 \mathrm{kV}$. This model corresponds to a more disturbed day than the day in question. Its polar cap is defined by a circle of radius $18.5^{\circ}$ centered on a point offset from the magnetic pole by $2^{\circ}$ in the antisunward direction. Model A and also model B have an enhanced dusk convection cell that simulates the observed dawn-dusk flow asymmetry. Model B is representative for a $K p$ of 3 and employs a cross-tail magnetospheric potential of $62 \mathrm{kV}$. This model is expected to be the most appropriate for the comparison with the radar data. The final model, model $\mathrm{C}$, corresponds to a $K p$ of 2 and cross-tail potential of $52 \mathrm{kV}$. However, for model $\mathrm{C}$ the convection pattern was assumed to have two symmetric cells. It should be noted that our association of a given convection model with a specific level of magnetic activity cannot be rigorously justified, but it reflects the general trend between crosstail potential and $K p$.

Figure 2 shows horizontal flow velocities for the 3 models as views by a corotating observer. The velocities are presented in a MLT invariant latitude frame, with the velocities being shown over a similar latitudinal range as obtained by the radar (see Figure 1). Model A velocities are shown in the upper panel; the enhanced dusk flow and both the noon and midnight flow reversal regions are evident. Flow speeds of $2 \mathrm{~km} / \mathrm{s}$ are found at 1800 MLT and $70^{\circ} \Lambda$, beyond which a region of antisunward polar cap flow is found. Model B (central panel) has similar flow characteristics, but the size of the polar cap and the flow speeds are reduced. In addition, the local time of the flow reversals at both noon and midnight are shifted to times nearer those observed (compare with Figure 1). The third model (lower panel) shows symmetric weak flow regions in the dawn and dusk sectors. Of the three models, model $B$ provides the best comparison with the observations with regard to flow directions, flow speeds, and the asymmetry between the dawn and dusk sectors.

Figure 3 shows a more quantitative comparison between the Millstone Hill radar data and the three models. In the left panel, the three radar scans that cross the region of $1800 \mathrm{LT}$ are plotted as a westward speed versus invariant latitude. Data sets 1,2 , and 3 are, respectively, the radar scans near the 1600,1700 , and 1800 LT meridians at $58^{\circ} \wedge$ shown in Figure 1 . An inferred ' 1800 ' LT curve has been drawn as a dashed line through these data. This inferred curve uses the velocity from the $1600 \mathrm{LT}$ scan at the most poleward extent, the velocity from the $1700 \mathrm{LT}$ scan at $70^{\circ}$ latitude and the velocities from the $1800 \mathrm{LT}$ scan between $56^{\circ}$ and $65^{\circ}$. These are the regions on the 1800 LT meridian crossed by the three scans (see
Figure 1). The model 1800 MLT flow speeds are shown in the right panel. The model A curve is, in general, too high and model $\mathrm{C}$ is too low. Model $\mathrm{B}$ gives reasonable quantitative agreement with the radar data in that both the peak speed and the fall-off with latitude are similar to those observed. The model has a fall-off with latitude that is proportional to the inverse of the sine of colatitude to the fourth power.

The variation of drift velocities observed at Millstone Hill (strong at dusk and weak at dawn) is probably related to the variation of magnetic activity on this day. Indeed, the Churchill magnetometer array situated about 2 hours $\left(25^{\circ}\right.$ longitude) to the west of Millstone Hill observed relatively quiet conditions for the period of observation, except for a 10 hour period from 1700 UT on October 13 to 0300 UT on October 14 when a series of about eight substorms occurred (John Walker, private communication, 1982). This period of high activity corresponds to about $1130 \mathrm{LT}$ to $2130 \mathrm{LT}$ (afternoon-early evening sector) at Millstone Hill. Hence, although our use of an asymmetric dusk enhanced time-independent convection pattern can be questioned, we believe that for Millstone Hill the model does correspond to the local observations.

In order to calculate the ion densities it is necessary to follow plasma flux tubes over at least 24 hours. This enables us to correctly account for the UT dependent variations associated with the offset between the geographic and geomagnetic poles (or in the MLT framework of Figure 1 the fact that the location of the terminator depends on UT). Figure 4 shows the plasma drift trajectories in an invariant latitude-MLT quasi-inertial frame. In this figure, the tendency of the plasma to corotate has been taken into account. Arrows indicate the general drift directions. Panels A, B, and C correspond to models A, B, and C. Each set of model trajectories appears as a twocell pattern but with different cell sizes. The largest cell size is associated with the most active model (model A). A plasma stagnation region, where sunward magnetospheric convection cancels corotation, is found in the 1900 to 2000 MLT sector for each model; however, the latitude of this region moves equatorward as the magnetic activity level increases.

Figure 5 shows contours of the horizontal convection drift speed for each model in the invariant latitude-MLT quasi-inertial frame. The enhanced plasma flow in the dusk sector for models A and B is clearly evident. All three models show fairly uniform flow speeds in the polar cap (with speeds between 150 and $500 \mathrm{~m} / \mathrm{s}$ ).

Figure 6 shows contours of the vertical component of the electromagnetic drift velocity for each model in the quasi-inertial frame. These vertical drifts arise because (except at the pole) there is a component of the $E \times B$ drift 

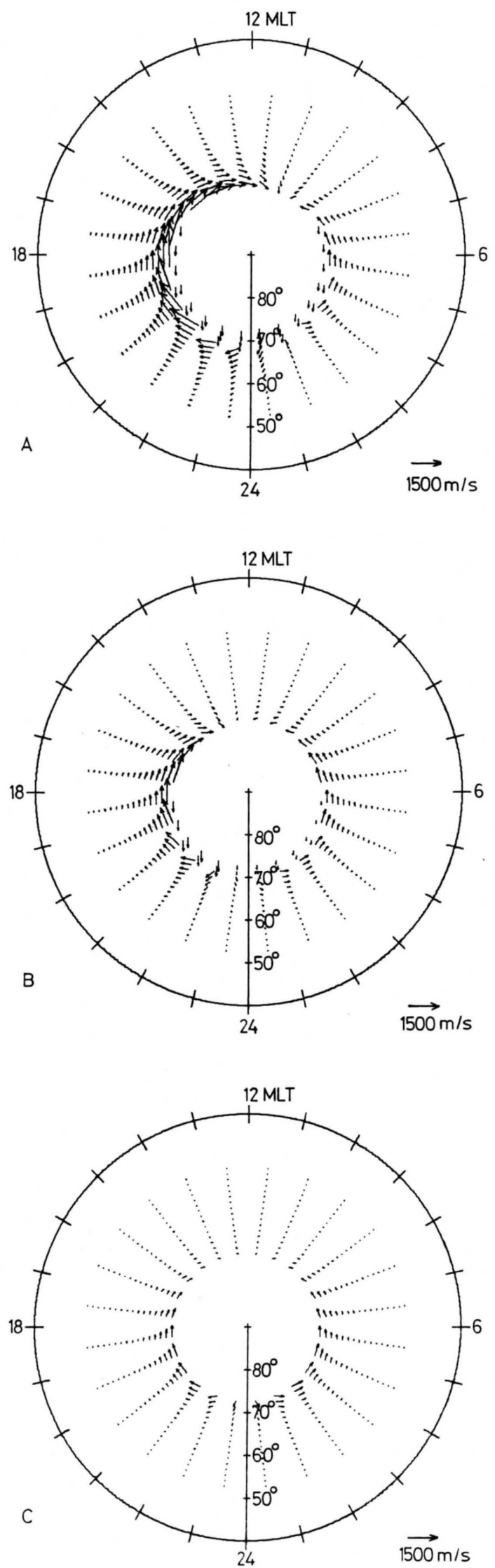

Fig. 2. Model ion drift velocity distributions for Millstone Hill. The velocities are displayed in an MLT-invariant latitude polar diagram. The panels A, B, and C correspond to the plasma convection models $A, B$, and $C$, respectively.
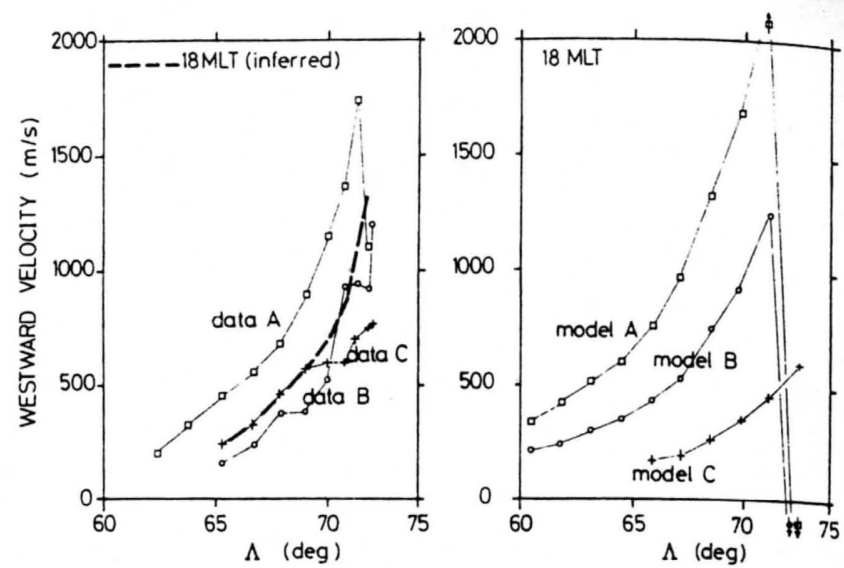

Fig. 3. Westward drift velocity component as a function of latitude as observed at Millstone Hill (left panel) and as predicted by the convection models (right panel). Data sets 1,2 , and 3 (left panel) are the latitudinal scans starting at 1600, 1700, and $1800 \mathrm{LT}$, respectively. Because the scanning track does not lie along a magnetic meridian, all three data sets cross the 1800 MLT meridian. The dashed line gives the inferred latitudinal variation along the 1800 MLT meridian. The right panel gives the latitudinal variation along the 1800 MLT meridian as predicted by the three plasma convection models.

in the vertical direction and are predominantly upward on the dayside (solid contours) and downward at night (dashed contours). The distribution of the upward and downward drifts has a marked effect on the loss/maintenance of plasma as well as on the shape of the $F$ region density profile. In models A (upper panel) and B (central panel) the vertical drift speeds range from $60 \mathrm{~m} / \mathrm{s}$ (upward) to $-60 \mathrm{~m} / \mathrm{s}$ (downward); however, the model B distribution shows a much higher degree of dawn-dusk asymmetry. In fact, model B has only a +20 to $-20 \mathrm{~m} / \mathrm{s}$ variation in the dawn sector, which is comparable to the last active model C.

Not shown in Figure 6, but also important for producing vertical ion drifts, is the effect of the neutral wind. The neutral wind in our model blows over the polar cap from 1300 to 0100 MLT and is such that around noon and below $70^{\circ} \wedge$ downward ion drifts of the order of 10 's of $\mathrm{m} / \mathrm{s}$ are produced, while around midnight and equatorward of $70^{\circ} \mathrm{\Lambda}$ upward drifts, also of the order of $10^{\prime} \mathrm{s}$ of $\mathrm{m} / \mathrm{s}$, are generated. On the dayside, the overall effect of the windinduced vertical drifts is overshadowed by the high production rates. By contrast, in the night sector production rates are low and vertical transport becomes very important. At mid-latitudes the neutral wind-induced upward drift acts to maintain the nighttime corotating $F$ region.

Figure 7 shows contours of the auroral precipitation energy flux used in the three models. The energy flux is in units of ergs $\mathrm{cm}^{-2} \mathrm{~s}^{-1} \mathrm{sr}^{-1}$. These auroral energy fluxes are the major source of nighttime ion production. In the model calculations the ion production rate profiles were attributed to electrons of the same auroral spectral shape everywhere, but of differing energy flux. The spectral shape adopted was that of auroral electrons with a characteristic energy of a few keV; see Knudsen et al. [1977]. None of the auroral precipitation models used in this study had discrete spatial structures, i.e., auroral arcs were not considered. The precipitation patterns used in models $\mathrm{B}$ and $\mathrm{C}$ are such that the ion production rate in 

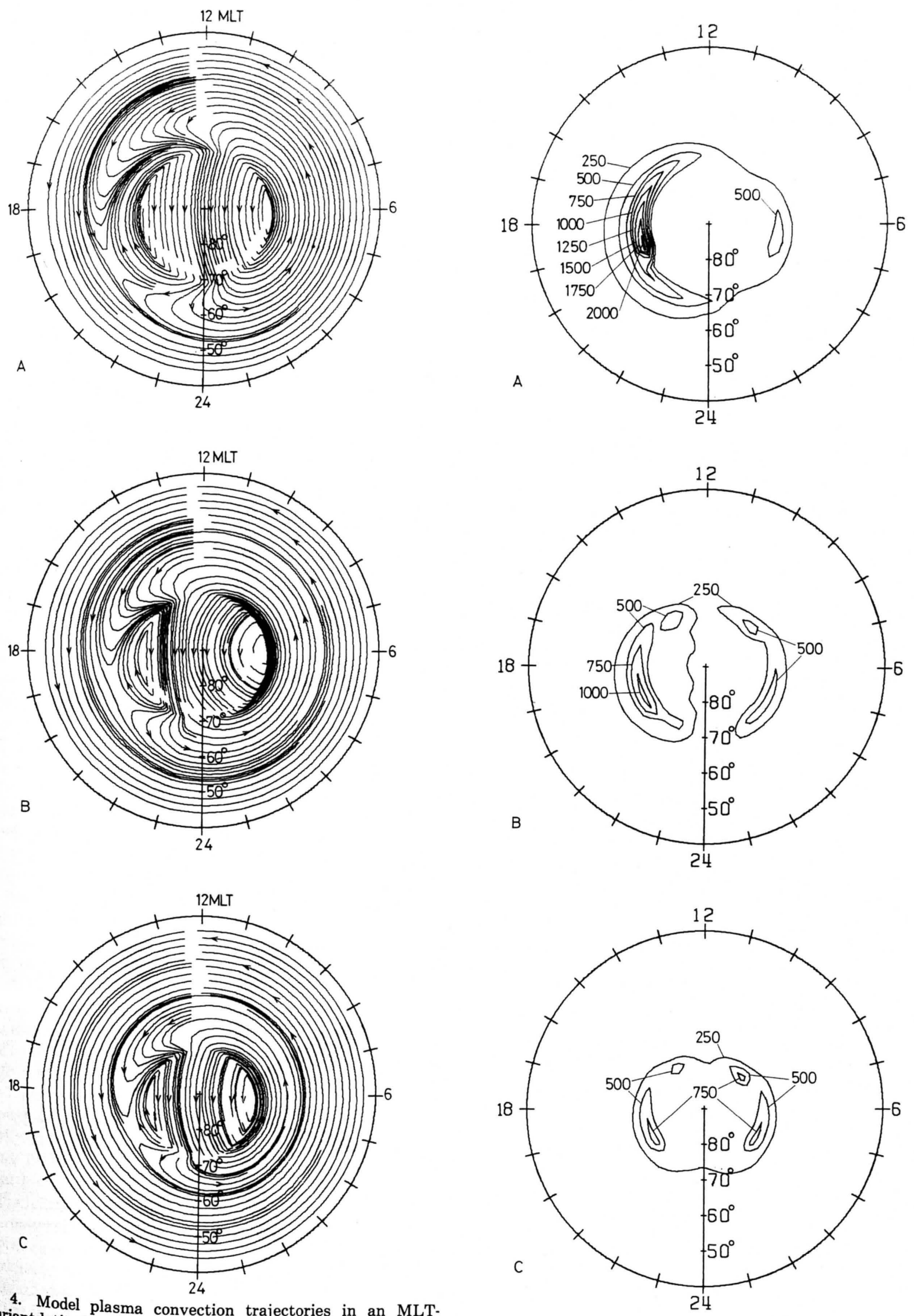

Fig. 4. Model plasma convection trajectories in an MLTindicate latitude polar diagram. The arrows on the trajectories pond to plasma flow direction. The panels A, B, and C corresThe plasma trajma convection models $\mathrm{A}, \mathrm{B}$, and $\mathrm{C}$, respectively. significant trajectories were followed starting from a region of the plotted traj production, which is indicated by the breaks in

Fig. 5. Contours of the model horizontal drift speed distributions as a function of MLT and invariant latitude. The contours are labeled in $\mathrm{m} / \mathrm{s}$, and the three panels correspond to the three plasma convection models. 

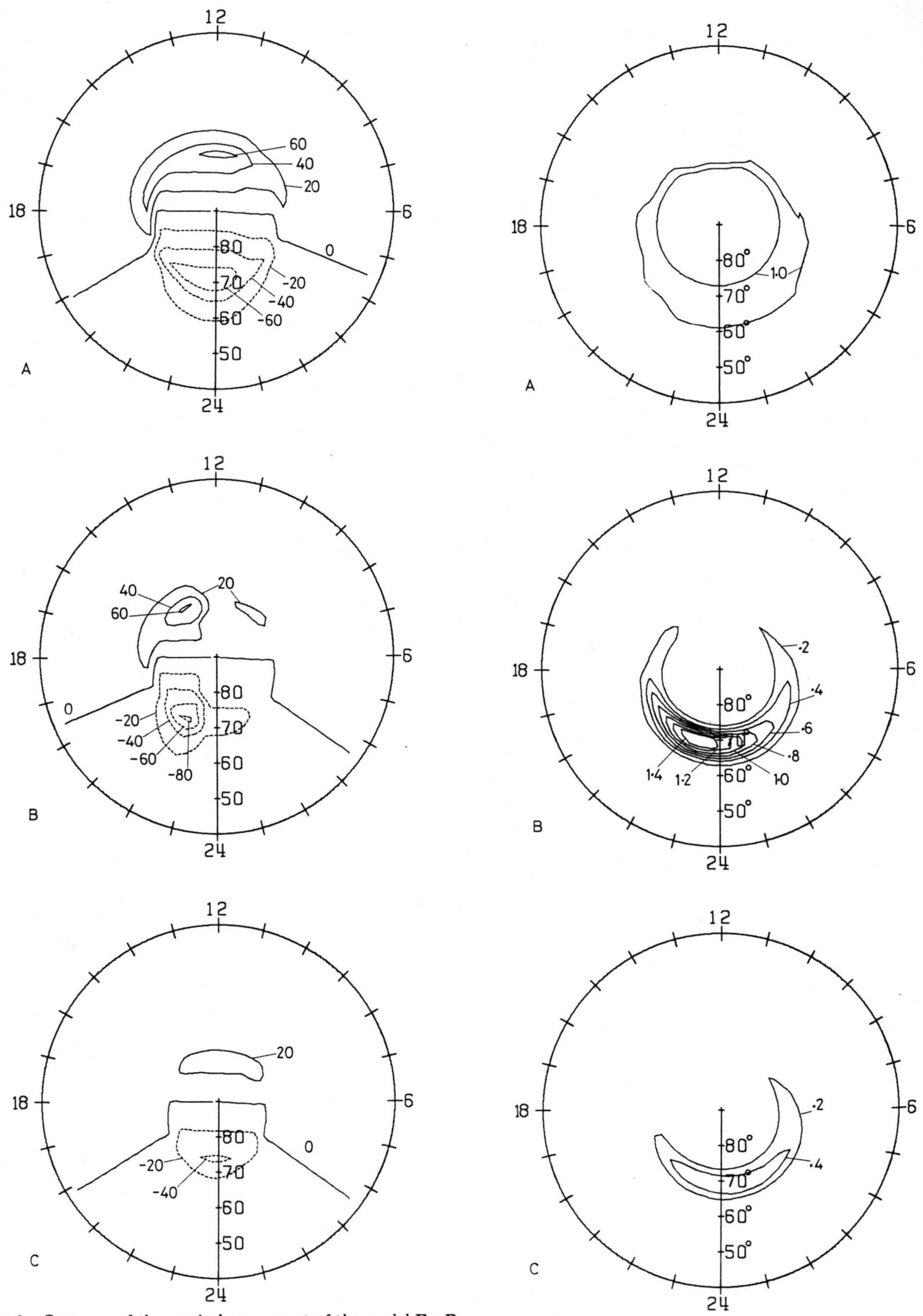

Fig. 6. Contours of the vertical component of the model $\mathbf{E} \times \mathbf{B}$ drift velocity as a function of MLT and invariant latitude. The contours are labeled in $\mathrm{m} / \mathrm{s}$, with the dashed contours representing downward drifts. The three panels correspond to the three convection models.

Fig. 7. Contours of the model auroral energy flux as a function of MLT and invariant latitude. The contours are labeled in units of ergs $\mathrm{cm}^{-2} \mathrm{~s}^{-1} \mathrm{sr}^{-1}$. 
the nocturnal auroral zone is fairly high [Spiro et al., 1982], and consequently, deep troughs or 'polar holes' are not expected to occur.

Since the data were obtained from October 13 to 14, the solar season was very close to equinox, and hence, approximately all of the geographic dayside was in sunlight. This means that in the magnetic quasi-inertial frame, the terminator moves $23^{\circ}$ over the magnetic pole on the noon-midnight meridian in 24 hours owing to the $11.5^{\circ}$ offset between the geographic and geomagnetic poles. Thus, the region in which there is solar EUV ion production varies significantly over 24 hours.

\section{Densities at $500 \mathrm{~km}$}

Plate 1 shows color coded Millstone Hill ion densities for the period 1326 UT on October 13, 1979 to 1321 UT on October 14, 1979. (Note: Plate 1 is shown in a separate section of the journal.) The densities were measured at an altitude of $500 \mathrm{~km}$, and are presented in an LT-dip latitude reference frame. Table 2 interrelates dip and invariant latitude for the Millstone Hill field of view. The highest densities are color coded red/purple, while the lowest densities are coded blue. A color key is shown on the right side of Plate 1 , covering the density range of $10^{4}$ to $4 \times 10^{6} \mathrm{~cm}^{-3}$. To produce this map, each 'cell' of latitude and local time occupied by a single measurement was assigned the observed density, and the color coding varied over the cell to smoothly match those in the four adjacent cells. Satellite echoes that have not been edited from the data give spuriously large values in some cells and provide some idea of the resolution achieved in the measurements. This data set represents the 24 hours of data acquired by the Millstone Hill radar and is not a 'snapshot' of the polar $F$ region density. The set begins at about $7 \mathrm{LT}$ and then moves to later local times as Millstone Hill corotates.

There are three major morphological features present in Plate 1; namely, a dayside high density region, a nightside mid-latitude trough, and a region of auroral precipitation poleward of the mid-latitude trough. The first region, that of high densities in excess of $4 \times 10^{5}$ $\mathrm{cm}^{-3}$, lies in the dayside from $1000 \mathrm{LT}$ to $1900 \mathrm{LT}$. This region is produced by solar EUV radiation, but it is not symmetrical about local noon. In our model the offset is due to the influence of horizontal plasma transport, which in this region is primarily corotation. At high altitudes the corotation of plasma causes the highest densities to appear several hours later in local time than the time of peak production in the $E$ and lower $F$ regions. This time delay reflects the time required for ionization to diffuse from low altitudes, where the ionization is produced, to high altitudes [see Sojka and Schunk, 1982]. The horizontal neutral wind also constributes to this effect by depressing the densities in the morning hours and increasing them in the evening.

Over the whole night sector a mid-latitude trough region is evident. The trough is deepest $\left(<7 \times 10^{4} \mathrm{~cm}^{-3}\right)$, widest (about $5^{\circ}$ of latitude), and reaches its most equatorward extent in the morning sector. In the evening sector, the trough density is only a factor of 2 less than that in the surrounding region in certain places and is quite narrow (about $2^{\circ}$ ). However, it can be seen that the trough extends past the sunlight terminator to about $1630 \mathrm{LT}$, where the ion production rate is still high.

Poleward of the mid-latitude trough there is a structured region of slightly higher densities extending from 1800 to $2400 \mathrm{LT}$. This region is in darkness and these enhanced densities are probably associated with ion production due to auroral precipitation. These 'auroral' densities are about $7 \times 10^{5} \mathrm{~cm}^{-3}$, while the densities in the surrounding regions are about $3.5 \times 10^{5} \mathrm{~cm}^{-3}$.

Plate 2 panels $\mathrm{A}, \mathrm{B}$, and $\mathrm{C}$ are, respectively, the ion density distributions at $500 \mathrm{~km}$ for models $\mathrm{A}, \mathrm{B}$, and $\mathrm{C}$ as seen by a corotating Millstone Hill observer. (Note: Plate 2 is shown in a separate section of the journal.) These densities are shown in an MLT-invariant latitude frame. A density color key is shown above the three panels; these colors were selected to be as similar as possible to those used in presenting the Millstone Hill data in Plate 1. The model densities were obtained from our UT dependent model over a period of 24 hours as the observer corotates around in local time. That is, each plot represents the behavior of flux tubes as they move through the region under radar surveillance. All three models are quite different from each other with regard to the convection electric field and auroral precipitation energy flux patterns. Of the three, model B is expected to give the best agreement, since the magnetospheric electric field and auroral precipitation energy flux are the most appropriate to the geomagnetic conditions that prevailed during the observation period. However, the other models are useful in showing the sensitivity of the $F$ region density to variations in these important magnetospheric input parameters.

In the dayside, the model $\mathrm{B}$ densities are greater than 4 $\times 10^{5} \mathrm{~cm}^{-3}$ over a wide region that extends from 1200 to $1800 \mathrm{LT}$, with the peak density approaching $10^{6} \mathrm{~cm}^{-3}$. This region is almost identical both qualitatively and quantitatively to the high density dayside region in Plate 1. Neither model A nor $\mathrm{C}$ have such a high density dayside region.

Model B shows a marked mid-latitude trough extending from $1700 \mathrm{LT}$ to $0730 \mathrm{LT}$. In the morning sector, the lowest density in the trough is about $6 \times 10^{4} \mathrm{~cm}^{-3}$, which is similar to that observed by the Millstone Hill radar. In the afternoon-evening sector, the trough does extend beyond $1800 \mathrm{LT}$, in agreement with the observations shown in Plate 1. These low densities are associated with flux tubes transported from the post sunset sector to the dayside on a time scale that is too short for a steady state equilibrium to be reached between the high density sunlit $E$ region and the depleted topside $F$ region. However, the model $\mathrm{B}$ trough is not shallow and narrow as indicated by the measurements. In contrast, model B shows a particularly deep 'hole' poleward of, but attached to, the evening sector trough. Also, the observed higher density 'auroral' type structures in Plate 1 are not present in model B in the 1800 to $2300 \mathrm{LT}$ region poleward of the trough.

For model A there is a region of high density poleward of the trough. Indeed, model A shows considerable 'fine structure' in the 1800 to 2400 MLT region. This structure is not directly related to the auroral precipitation pattern 
(compare with Figure 7, panel A). Thus, although model $\mathrm{A}$ is not directly comparable to the observed data because of the high activity level, it does suggest that the shortcomings of model B in the 1800 to 2300 MLT trough sector could be due to a lack of auroral production at the appropriate flux levels. This is not particularly surprising, since the model B auroral precipitation pattern was based on an average energy flux for the particular activity level. However, on a given day the auroral precipitation energy fluxes could be different from the average fluxes. Apart from this small but important region, model B shows good agreement, both qualitatively and quantitatively, with the observed Millstone Hill data shown in Plate 1.

\section{Detailed Afternoon-Evening SECTOR COMPARISON}

The principal discrepancy between the model B densities and the observations occurs in the high latitude evening sector in a region of westward plasma flow. This is also the region where discrete arc formations are expected, although the model only allows for diffuse 'weak' precipitation. Figure 8 shows both the Millstone Hill radar densities and plasma flow velocities at $500 \mathrm{~km}$ in an invariant latitude-MLT frame. The densities are represented by contour lines labelled in units of $\log _{10}\left[N_{e}\right.$ $\left.\left(\mathrm{cm}^{-3}\right)\right]$. In the 1400 to $2200 \mathrm{LT}$ period, the flow is strongest at high latitudes and predominantly westward when viewed by the radar. Only in the 2100 to $2200 \mathrm{LT}$ region above $68^{\circ} \wedge$ is the flow seen to be coming out of the polar region, moving both southeast and southwest. A well-defined trough region with densities less than $10^{5}$ $\mathrm{cm}^{-3}$ is found between 1700 and $2200 \mathrm{LT}$ in a narrow latitude band extending from $64^{\circ}$ to $68^{\circ} \Lambda$. Polward of this trough is a narrow region of relatively high densities, $\sim 7$ $\times 10^{5} \mathrm{~cm}^{-3}$. In both the trough and high density regions the plasma is flowing westward with speeds of 100 to 300 $\mathrm{m} / \mathrm{s}$ and 300 to $500 \mathrm{~m} / \mathrm{s}$, respectively, relative to the corotating observer. The extension of the trough into the daylight sector coincides with a region of very high westward flow velocities (1-1.5 $\mathrm{km} / \mathrm{s})$.

The corresponding model $\mathrm{B}$ densities and flow velocities are shown in Figure 9. As expected, the densities in the late evening high-latitude sector are considerably lower. However, the general flow properties are similar, although less structured, and the equatorward region of the mid-latitude trough shows a somewhat similar density structure, including a high-latitude pre-1800 MLT feature. Indeed, by simply introducing a slight latitudinal fine structure in the convection model it would be possible to match the observed trough density structure. This, however, would not be adequate for the region poleward of the trough.

For model B the region of low densities between 1900 and 2200 MLT is associated with very large downward drifts (Figure 6, panel B) and relatively low average auroral energy fluxes (Figure 7, panel B). Since this region is also in darkness, the large downward drifts dominate, causing the $F$ region peak to be lowered into a region of greater recombination rate and, consequently, the density decreases. In order to overcome this effect,
TABLE 2. Transformation from DIP to Invariant latitude

\begin{tabular}{cc}
\hline Dip, deg & Invariant, deg \\
\hline 75.0 & 70.6 \\
70.0 & 65.6 \\
65.0 & 61.3 \\
60.0 & 57.1 \\
55.0 & 53.1 \\
50.0 & 48.8 \\
\hline
\end{tabular}

either the vertical downward drift must be reduced or the region must have a strong production source, i.e., an aurora. The band of high densities observed by the radar poleward of the mid-latitude trough (Figure 8) is indicative of the presence of strong precipitation. Such precipitation is indeed present. Figure 10 shows a defense meteorological satellite program (DMSP-F4) auroral image taken between 0210 and 0240 UT (October 14, 1979) over the eastern sector of North America at a local time of about 2200 LT. In this image the darkest shades correspond to regions of high photon emission. As a result, the major cities on the eastern seaboard and around the Great Lakes are dark, while the Atlantic Ocean and the uninhabited northern portions of Canada are white. A geographic coordinate system is given by the broken lines. Between latitudes of $56^{\circ}$ and $58^{\circ} \mathrm{N}$ is a welldefined auroral arc extending over several hours of local time ( $35^{\circ}$ of longitude at least). This image was taken while the Millstone Hill radar was scanning the same region of the high latitude ionosphere, and therefore, this arc should have produced a relatively high rate of ionization in the $E$ region at that time. Aurora were also present in the adjacent DMSP images from the F3 satellite in the midnight sector; however, at these times Millstone Hill was at different local times.

The arc observed by the DMSP satellite in Figure 10 is located approximately $1^{\circ}$ to $2^{\circ}$ poleward (or 1 to 2 hours in local time eastward) of the high density region observed by Millstone Hill between 2100 and $2200 \mathrm{LT}$ at $500 \mathrm{~km}$ (Figure 8). This displacement is consistent with the configuration of an $E$ region production source in a westward convection region, since the density at $500 \mathrm{~km}$ will take on the order of an hour to respond owing to the long diffusion time constant. Therefore, at $500 \mathrm{~km}$ the highest densities would be expected somewhat westward of the low altitude production source. Such time delays and displacements at high altitudes of low-altitude features are described in the storm study of Sojka and Schunk [1983].

Hence, the presence of a discrete arc in the evening sector adequately explains the Millstone Hill radar observations. The arc not only produces a region of high density, but acts to restrict the poleward extent of the midlatitude trough. In our model, discrete arcs are not taken into account; instead, average auroral precipitation distributions are used. Although an average distribution of precipitation is adequate for comparisons with a large data base, its shortcomings in this particular type of study is a major disadvantage. In order to improve significantly the auroral model used in this study, it would be necessary to have a more extensive auroral image coverage than that afforded by the DMSP satellites on October 13 and 14, 1979. 
The latitude of the midnight and morning sector troughs for the observation and model B are different (see Plates 1 and $2 b$ ). After midnight the model trough lies about $5^{\circ}$ equatorward of the observed trough; however, in the afternoon and early evening sectors the locations are in good agreement. A probable cause of this discrepancy lies in the model convection pattern, which has an enhanced convection cell in the dusk sector that extends to midnight. Hence, in the model the midnight location of the trough is determined by this high activity sector. From midnight onward (the weak convection cell region) the midnight trough is located in a region of corotation, and hence, the morning sector model trough remains at the same latitude as it corotates. As mentioned earlier, the disturbed activity conditions ended at about $2130 \mathrm{LT}$ (Millstone Hill). Hence the ionosphere would have begun to corotate at a fixed latitude at about 2130 LT. At this time, the model and observed trough locations are very similar, and if we had been able to change the convection model to a quiet convection pattern at this time, the $5^{\circ}$ trough location discrepancy would have been removed.

\section{SUMMARY}

We have compared the predictions of our high-latitude ionospheric model with the diurnal variations of plasma convection velocities and electron densities observed at Millstone Hill on a geomagnetically moderately active day near equinox. Since the time-dependent variation of the magnetospheric electric field was not known, we calculated plasma drift velocities and ion densities for three different convection/precipitation models, each corresponding to a different level of magnetic activity. However, for each model, the cross-tail magnetospheric electric potential was kept constant for the duration of the study. The model calculations for the magnetic activity level that best described the conditions occurring on the observation day produced plasma drift velocities and electron densities that were in good agreement, both qualitatively and quantitatively, with the measurements. The other two models were useful for showing the sensitivity of the high-latitude ionosphere to magnetospheric convection and precipitation.

From our comparison of model predictions and Millstone Hill observations, we found the following:

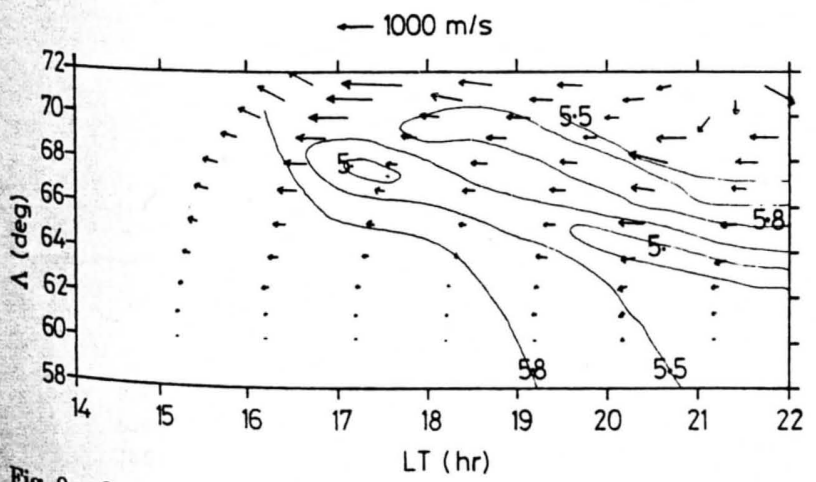

Fig. 8. Superposition of the observed plasma flow and density horizon the 1400-2200 LT sector. The arrows represent the unitental velocities, and the contours represent ion densities in units of $\log _{10}\left[N_{e}\left(\mathrm{~cm}^{-3}\right)\right]$

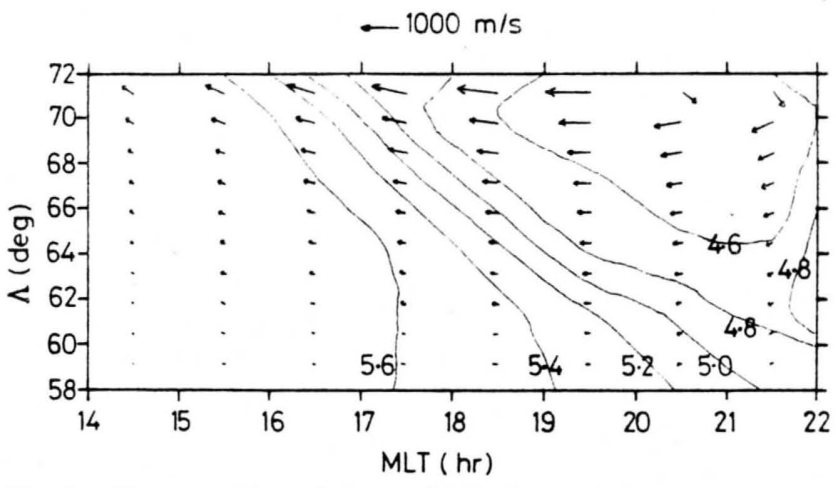

Fig. 9. Superposition of the model B plasma velocities and densities in the 1400-2200 MLT sector. The display format is otherwise identical to Figure 8.

1. On the observation day, the magnetospheric convection pattern observed by the Millstone Hill radar was consistent with a two-cell, asymmetric pattern with enhanced plasma flow in the dusk sector, with flow speeds reaching $1.5 \mathrm{~km} / \mathrm{s}$. In the dusk strong convection cell, the fall-off of the magnetospheric potential with latitude was proportional to the inverse of the sine of colatitude to the fourth power.

2. On the dayside, a region of high density $\left(\gtrsim 4 \times 10^{5}\right.$ $\mathrm{cm}^{-3}$ ) occurred at $500 \mathrm{~km}$ in the $1000-1900 \mathrm{LT}$ sector. Although this region results from ion production due to solar EUV radiation, it was not symmetrical about local noon, owing to horizontal transport. The shift in the high density region toward the afternoon reflects the time required for ionization to diffuse from low altitudes, where it is produced, to high altitudes. Neutral wind effects are also important in modifying the daytime density variation.

3. On the observation day, the nocturnal mid-latitude trough was the deepest $\left(<7 \times 10^{4} \mathrm{~cm}^{-3}\right)$, the widest $\left(\sim 5^{\circ}\right.$ of latitude), and reached its most equatorward position in the morning sector. In the evening sector, the trough was partially filled in by production due to a discrete auroral arc, a feature not included in our ionospheric model. However, the evening sector trough did extend past the terminator to about 1630 LT. The model calculations indicated that this extension was primarily due to the transport of low density nightside flux tubes to the dayside.

4. The model, which is based on average auroral precipitation fluxes, can describe the gross features of the enhanced densities in the auroral zone. However, the observations indicate that discrete auroral arcs are important and need to be included if details in the observations are to be reproduced.

5. Large scale production, vertical diffusion, $a$ horizontal transport can create 'fine structure' in the modeled electron density distribution that could be confused with 'auroral fine structure' if care is not exercised.

We have not attempted to 'fine-tune' any of the models by adjusting parameters in an effort to obtain better agreement with the data. Such an effort does not seem warranted at this time, owing to the limitations of both the model and the data. A more comprehensive comparison requires a multiple-site observation of the plasma 


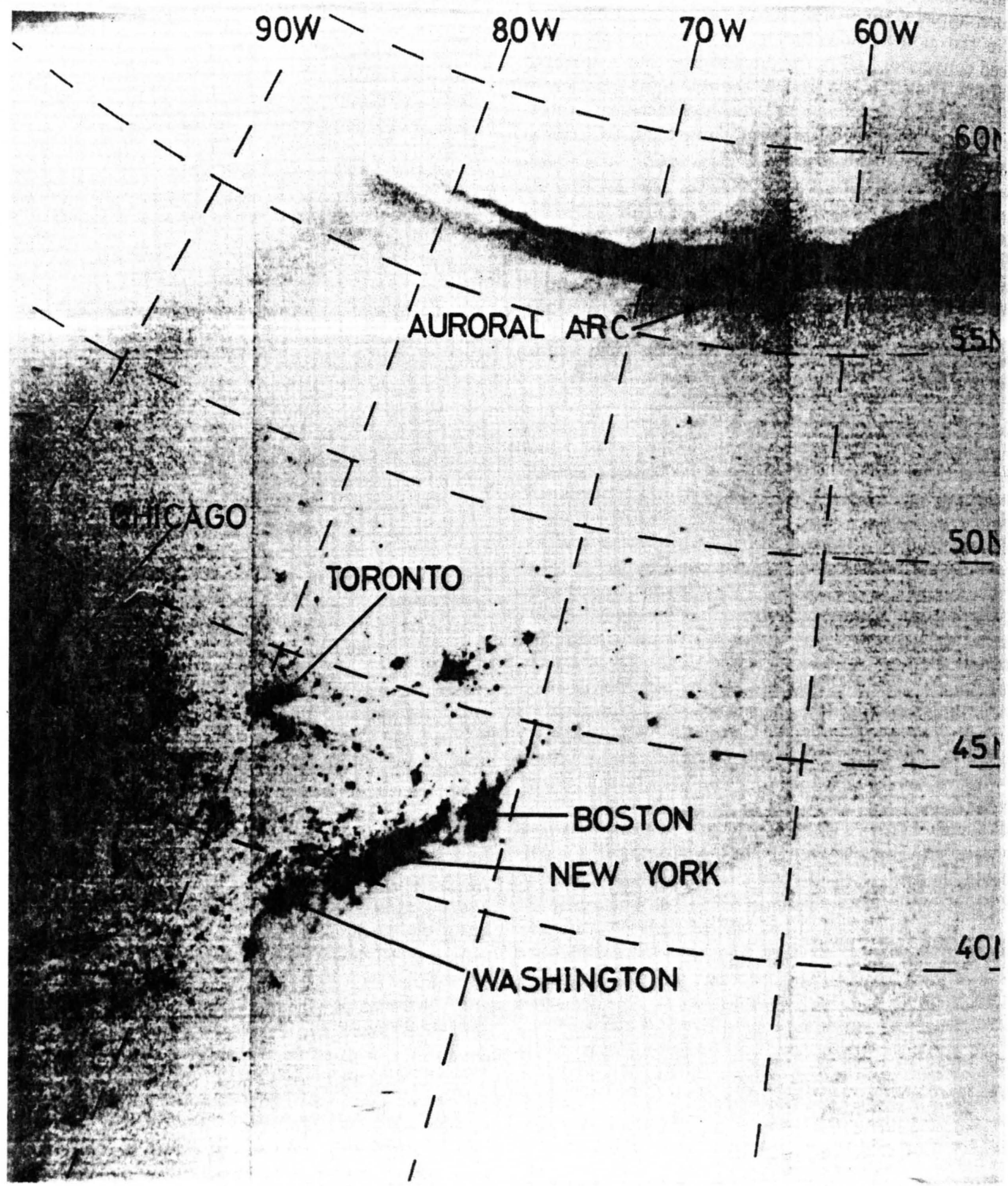

Fig. 10 DMSP satellite image of the eastern part of North America. The image was taken when the Millstone Hill radar was making a latitudinal scan at 1800 LT. Superimposed on the image is the geographic coordinate system. Note the bright auroral arc in the upper part of the figure. Also shown are the city lights of the major east coast cities. 
convection pattern and a more extensive auroral image coverage of discrete arcs.

\begin{abstract}
Acknowledgements. This research was supported by NASA Acknowled-77 and NSF grant ATM-8217138 to Utah State University and NSF grant ATM-8119812, which supported the Univerations of the Millstone Hill radar. The computer modeling effort was supported by the National Center for Atmospheric Research, which is sponsored by the National Science Foundation. The aurora imagery data from U.S. Air Force satellites tere made available by the Air Weather Service through the National Geophysical and Solar-Terrestrial Data Center, EDS, NOAA, Boulder, Colorado.

The Editor thanks A. D. Richmond and another referee for their assistance in evaluating this paper.
\end{abstract}

\section{REFERENCES}

Brinton, H. C., J. M. Grebowsky, and L. H. Brace, The highlatitude winter $F$ region at $300 \mathrm{~km}$ : Thermal plasma observations from AE-C, J. Geophys. Res., 83, 4767-4776, 1978.

Evans, J. V., Ionospheric movements measured by incoherent scatter: A review, J. Atmos. Terr. Phys., 34, 175-209, 1972.

Holt, J. M., R. H. Wand, and J. V. Evans, Millstone Hill measurement, February 26, 1979, during the solar eclipse and formation of a mid-day $F$ region trough, J. Atmos. Terr. Phys., in press, 1983.

Knudsen, W. C., P. M. Banks, J. D. Winningham, and D. M. Klumpar, Numerical model of the convecting $F_{2}$ ionosphere at high-latitude, J. Geophys. Res., 82, 4784, 1977.

Richmond, A., et al., An empirical model of quiet-day ionospheric electric fields at middle and low latitudes, $J$. Geophys. Res., 85, 4658-4664, 1980.

Schunk, R. W., and W. J. Raitt, Atomic nitrogen and oxygen ions in the daytime high-latitude $F$ region, $J$. Geophys. Res., 85 , 1255-1272, 1980.

Schunk, R. W., and J. J. Sojka, Ion temperature variations in the daytime high-latitude $F$ region, J. Geophys. Res., 87, 5169-5183, 1982a.

Schunk, R. W., and J. J. Sojka, Ionospheric hot spot at high latitudes, Geophys. Res. Lett., 9, 1045-1048, 1982 b.
Sojka, J. J., and R. W. Schunk, Predicted diurnal variations of electron density for three high-latitude incoherent scatter radars, Geophys. Res. Lett., 9, 143, 1982.

Sojka, J. J. and R. W. Schunk, A theoretical study of the high latitude $F$ region's response to magnetospheric storm inputs, J. Geophys. Res., 88, 2112-2122, 1983.

Sojka, J. J., J. C. Foster, W. J. Raitt, R. W. Schunk, and J. R. Doupnik, High-latitude convection: Comparison of a simple model with incoherent scatter observations, J. Geophys. Res., 85, 703-709, 1980.

Sojka, J. J., W. J. Raitt, and R. W. Schunk, A theoretical study of the high-latitude winter $F$ region at solar minimum for low magnetic activity, J. Geophys. Res., 86, 609-621, 1981a.

Sojka, J. J., W. J. Raitt, and R. W. Schunk, Theoretical predictions for ion composition in the high-latitude winter $F$ region for solar minimum and low magnetic activity, J. Geophys. Res., 96, 2206-2216, $1981 b$.

Sojka, J. J., W. J. Raitt, and R. W. Schunk, Plasma density features associated with strong convection in the winter highlatitude $F$ region, J. Geophys. Res., 86, 6908-6916, 1981c.

Sojka, J. J., R. W. Schunk, and W. J. Raitt, Seasonal variations of the high-latitude $F$ region for strong convection, $J$. Geophys. Res., 87, 187-198, 1982a.

Sojka, J. J., W. J. Raitt, R. W. Schunk, F. J. Rich, and R. C. Sagalyn, Observations of the diurnal dependence of the highlatitude $F$ region ion density by DMSP satellites, $J$. Geophys. Res., 87, 1711-1718, $1982 b$.

Spiro, R. W., P. H. Reiff, and L. J. Maher, Precipitating electron energy flux and auroral zone conductances-An empirical model, J. Geophys. Res., 87, 8215-8227, 1982.

J. J. Sojka and R. W. Schunk, Center for Atmospheric and Space Sciences, Utah State University, Logan, UT 84322.

J. V. Evans, J. M. Holt, and R. H. Wand, Haystack Observatory, Massachusetts Institute of Technology, Westford, MA 01886.

(Received January 4, 1983; revised May 9, 1983; accepted May 18, 1983.) 